\title{
CORPORATE INCOME TAXATION OF MULTINATIONALS AND UNEMPLOYMENT
}

\author{
THOMAS EICHNER \\ MARCO RUNKEL
}

CESIFO WORKING PAPER NO. 1868

Category 1: Public FinAnCE

DECEMBER 2006

An electronic version of the paper may be downloaded

- from the SSRN website:

- from the RePEc website:

www.SSRN.com

Www.RePEc.org

- from the CESifo website: www.CESifo-group.de 


\title{
CORPORATE INCOME TAXATION OF MULTINATIONALS AND UNEMPLOYMENT
}

\begin{abstract}
Within a two-country model with involuntary unemployment, this paper investigates corporate income taxation under separate accounting versus formula apportionment. In contrast to separate accounting, under formula apportionment the corporate tax policy causes a fiscal externality which goes back to unemployment. This unemployment externality is the lowest when the apportionment formula does not contain a payroll factor. It tends to compensate other externalities such that tax rates become inefficiently low. In an empirical calibration, we show that the transition from separate accounting to formula apportionment improves welfare and reduces unemployment. The welfare increase is the strongest under a pure sales formula.
\end{abstract}

JEL Code: H25, H71, J60.

Keywords: separate accounting, formula apportionment, unemployment.

\author{
Thomas Eichner \\ Department of Economics \\ University of Siegen \\ Hölderlinstr. 3 \\ 57068 Siegen \\ Germany \\ eichner@vwl.wiwi.uni-siegen.de
}

\author{
Marco Runkel \\ Department of Economics \\ University of Munich \\ Ludwigstr. 28 / Vgb. / III \\ 80539 Munich \\ Germany \\ marco.runkel@Irz.uni-muenchen.de
}

15th November 2006 


\section{Introduction}

Corporate income taxation of multinational enterprises (MNEs) can basically follow two principles. Under separate accounting, profit of a MNE is taxed in the country where the MNE it declares. This principle is in operation mainly at the international level. Under formula apportionment, in contrast, corporate income of a MNE is first consolidated and then allocated back to the taxing countries according to a certain formula which idealistically reflects the activities of the MNE in the countries. The formula typically contains the capital (property), sales and/or payroll shares of the MNE in the taxing countries. Formula apportionment is applied at the national level, for example, in the US, Canada and Germany. Recently, the discussion of the relative merits of the two tax principles received a renewed interest both among politicians and researchers since the European Commission (2001) presented plans to replace separate accounting by formula apportionment within the boarders of the European Union.

This renewed interest is also reflected by an increasing number of economic studies on separate accounting versus formula apportionment. The initial study of Gordon and Wilson (1986) has recently been augmented by, for example, Eggert and Schjelderup (2003), Nielsen et al. (2003, 2004), Pethig and Wagener (2003), Sørensen (2004), Kind et al. (2005), Gérard (2005, 2006) and Riedel and Runkel (2006). This literature shows that the comparison of the two tax principles is basically a theory of fiscal externalities. Under separate accounting, corporate taxation causes a profit shifting externality as the individual country does not take into account that an increase in its tax rate induces MNEs to shift profit and, thus, taxable resources to other countries. This externality is positive and points to inefficiently low tax rates. Under formula apportionment, corporate taxation causes a tax base externality and a formula externality since one country's tax rate influences the other countries' tax revenues by a reduction in the MNEs' consolidated tax bases and an increase in the share of these tax bases assigned to other countries. The two externalities are opposite in sign but within a simple model Haufler (2006) shows that the sum of both is positive pointing to inefficient undertaxation, as the profit shifting externality under separate accounting. Nevertheless, the existence of positive corporate incomes implies that there is always a tax exporting effect à la Huizinga and Nielsen (1997) so that under both tax principles there additionally emerges a negative income externality which may render tax rates 
inefficiently high.

All above mentioned studies either totally ignore labor as a factor of production or consider perfect labor markets with full employment. Obviously, reality draws a quite different picture. Since the early seventies the member countries of the EU have been suffering from drastically growing unemployment. According to Eurostat data, the average unemployment rate in the EU-25 countries is currently around $9 \%$. Even though unemployment in the US is typically lower than in the EU, also the US faces an unemployment problem. The current unemployment rate in the US is about $5 \% .{ }^{1}$ It is therefore interesting to observe that the previous mentioned literature paid so little attention to the question how unemployment affects the efficiency of corporate income taxation under the two tax principles. Moreover, policy makers often view corporate taxation as a mean to attract firms and create jobs. Hence, independent of efficiency considerations it may be asked whether a tax reform in the EU from separate accounting to formula apportionment has a positive or negative effect on unemployment.

The present paper addresses such questions. It investigates corporate income taxation in a model with involuntary unemployment. We develop a two-country model with a representative MNE. In each country, the MNE produces an output good with capital and labor as inputs. The MNE may shift profit from one country to the other by, for example, distorting transfer prices or the debt-equity structure. Unemployment is modeled in the most simplest way. We assume that due to minimum wage legislations or the influence of labor unions the wage rate is fixed at a level above the equilibrium wage rate so that labor demand falls short of labor supply. Each country is populated by a continuum of households some of which are unemployed due to the labor market imperfection. The countries impose a corporate income tax on the MNE and noncooperatively choose their tax rates in order to maximize welfare of their residents. Corporate taxation either follows the principle of separate accounting or that of formula apportionment. Under the latter, consolidated profit is apportioned according to the property, sales and/or payroll shares of the MNE.

Within this model, we first identify the fiscal externalities caused by corporate income taxation. Under separate accounting, it turns out that taking into account unemployment does not add a further fiscal externality since the corporate tax rate in one

\footnotetext{
${ }^{1}$ All these data are taken from the Eurostat website under http://epp.eurostat.cec.eu.int.
} 
country leaves unchanged the MNE's labor demand and unemployment in the other country. In contrast, under formula apportionment a cross country effect of corporate taxation on unemployment emerges for two reasons. First, corporate taxes fall on the consolidated tax base so that an increase in one country's tax rate induces the MNE to reduce labor demand in both countries (tax base effect). Second, as a reaction on a tax increase in one country the MNE reallocates labor to the other country in order to reduce the share of consolidated profit which the apportionment formula assigns to the tax increasing country (formula effect). These two effects are not taken into account by the countries when choosing their tax rates and, thus, they constitute an unemployment externality which so far has been ignored in the literature. In general, the sign of the externality is ambiguous since tax base and formula effect go into opposite directions. But for a Cobb-Douglas production function the unemployment externality turns out to be positive pointing to inefficient undertaxation. As intuitively plausible, it is the lowest when the apportionment formula does not contain a payroll factor.

We also investigate the interplay of the unemployment externality and the externalities already known from previous studies. Similar to Haufler (2006) we show that the sum of tax base and formula externalities is positive. Moreover, if the production elasticity of labor in the Cobb-Douglas production function is sufficiently large, the unemployment externality will be strong enough to outweigh the income externality such that the sum of both is positive, too. Under formula apportionment, the corporate income tax rates are then inefficiently low. This result is to a large extent driven by the unemployment externality since it compensates the income externality, i.e. that externality which may be responsible for too high tax rates if unemployment is ignored. In addition, starting from the assumption that tax rates under formula apportionment are inefficiently low, we show that the efficiency gap will be minimized if the apportionment formula exclusively uses a sales factor since in this case both the unemployment externality and the formula externality are smallest. These insights are confirmed and augmented by an empirical calibration of the model to the EU-25 countries. It turns out that separate accounting causes inefficiently high tax rates and unemployment. Introducing formula apportionment would bring down tax rates and unemployment below the efficient level, but welfare is still higher than under separate accounting. The welfare increase is the highest with a pure sales formula. 
To the best of our knowledge, the only study investigating formula apportionment in the presence of unemployment is that of Goolsbee and Maydew (2000). In contrast to our analysis, however, they do not theoretically analyze the implications of unemployment under formula apportionment. Instead, using a natural experiment from the US they empirically test the effect of a change in the formula design on employment. Their main finding is that a decrease in the formula weight on payroll in one state enhances employment in that state and reduces employment in other states. Hence, they analyze externalities caused by the formula weights and not those caused by the tax rates which are the main interest of our analysis. ${ }^{2}$ It should also be noted that there are models on capital tax competition with unemployment, for example, Gabszewicz and Ypersele (1996), Lejour and Verbon (1998), Fuest and Huber (1999), Richter and Schneider (2001) and Ogawa et al. (2006). However, theses studies focus on a wealth tax on capital and do not consider separate accounting versus formula apportionment.

The paper is organized as follows. Section 2 sets up the model which is used in Section 3 to study corporate income taxation under separate accounting. In Section 4, we turn to formula apportionment and Section 5 contains the calibration of the model to EU-25. Section 6 concludes.

\section{The Model}

Multinational Enterprises. Consider a model with two identical countries denoted by $a$ and $b$. The countries are small in comparison to the rest of the world. There is a large number of identical MNEs operating a plant in each country. Since MNEs are identical, it suffices to focus on a representative MNE. In country $i \in\{a, b\}$, the MNE produces a numeraire good according to the technology $F\left(k_{i}, \ell_{i}, q_{i}\right)$. The factors of production are mobile capital $k_{i}$, immobile labor $\ell_{i}$ and a third fixed factor $q_{i}$, say, entrepreneurial services. Since $q_{i}$ is fixed, it is suppressed when no ambiguities arise. The production function has positive and decreasing marginal returns to each input, i.e. $F_{x}>0, F_{x x}<0$ for all $x \in\left\{k_{i}, \ell_{i}, q_{i}\right\}$. It exhibits constant returns to scale with respect to all three production factors and decreasing returns to scale with respect to capital and labor. Hence, the fixed factor gives rise to a positive pure (economic)

\footnotetext{
${ }^{2}$ In the US, the formula design is under the control of the states and not the federal government.
} 
profit. Labor and capital are complements in the sense that $F_{k \ell}>0$. In addition, the production technology is concave in labor and capital, i.e. $F_{k k} F_{\ell \ell}-F_{k \ell}^{2}>0$.

The MNE is able to influence its tax liability by profit shifting activities. For example, it may misreport transfer prices of goods and services traded between the affiliates in the two countries or it may manipulate its debt-equity structure to shift profit from one country to the other (e.g. Hines 1999, Clausing 2003). In a stylized way, these activities are summarized in the variable $s$. If $s>0$, the MNE will shift profit from the subsidiary in country $a$ to the subsidiary in country $b$. For $s<0$ shifting is the other way round. But profit shifting is not costless. It comes at a concealment cost represented by the function $C(s)$. This cost reflects, for example, the risk of being detected when manipulating transfer prices or the debt-equity structure, or the cost of hiring tax consultants (Kant, 1988, Haufler and Schjelderup, 2000). It is supposed to satisfy $C(0)=C^{\prime}(0)=0, \operatorname{sign} C^{\prime}(s)=\operatorname{sign} s$ and $C^{\prime \prime}(s)>0$. Hence, the concealment cost is U-shaped with a minimum at $s=0$ where the MNE does not shift profit.

Economic profit of the MNE in country $i$ equals sales (output) less labor and capital costs and adjusted by profit shifting. The MNE's tax base in country $i$ will deviate from economic profit if the government grants only partial depreciation allowances and/or allows the MNE to deduct the cost of debt but not the cost of equity. We denote the fraction of capital cost that is deductible by the parameter $\rho \in[0,1]$ which comprises the cases of full, partial and no deductibility. The tax base of the MNE in country $a$ and $b$, respectively, is then given by

$$
\phi_{a}=F\left(k_{a}, \ell_{a}\right)-w_{a} \ell_{a}-\rho r k_{a}-s, \quad \phi_{b}=F\left(k_{b}, \ell_{b}\right)-w_{b} \ell_{b}-\rho r k_{b}+s,
$$

where $r$ is the world market interest rate and $w_{i}$ is the wage rate in country $i$. The interest rate is exogenously given since we assume that the two countries are small relatively to the rest of the world. The wage rates are fixed due to the labor market imperfections. A detailed description of the labor market is presented below.

Residents. Country $i$ is inhabited by immobile residents. Each resident is endowed with $\bar{k}$ units of capital which she inelastically supplies at the world capital market and one unit of labor which she inelastically supplies at the labor market in her country. Without loss of generality, the mass of residents in each country is normalized to one. Residents are divided into two groups: employed and unemployed individuals. 
Members of the first group are indicated by the superscript $e$. They earn income from three sources: wage income $w_{i}$, capital income $r \bar{k}$ and a share $\theta_{i} \in[0,1]$ of the MNE's total after-tax profit $\pi$. Unemployed individuals are denoted by the superscript $u$. They do not get a wage income and, thus, their disposable income composes of capital and profit income only. An individual of type $j$ in country $i$ uses its income to buy a private consumption good in quantity $x_{i}^{j}$. Its budget constraint can be written as

$$
x_{i}^{j}= \begin{cases}w_{i}+\theta_{i} \pi+r \bar{k}, & j=e, \\ \theta_{i} \pi+r \bar{k}, & j=u .\end{cases}
$$

Its preferences are represented by the quasi-linear utility function

$$
U\left(x_{i}^{j}, g_{i}\right)=\lambda x_{i}^{j}+V\left(g_{i}\right)
$$

where $g_{i}$ is the quantity of a locally provided public good in country $i$. Utility in (3) is linear in the private good and increasing and concave in the public good, i.e. $V^{\prime}\left(g_{i}\right)>0$ and $V^{\prime \prime}\left(g_{i}\right) \leq 0$. By assuming quasi-linearity we abstract from income effects in the demand for the public good. As will be explained below, the reason for introducing the preference parameter $\lambda$ is a technical one. By setting $\lambda=0$ we are able to consider the special case in which governments maximize tax revenue instead of welfare.

Unemployment. As labor is immobile, there is a local labor market in each country. On country $i$ 's labor market, the MNE's demand $\ell_{i}$ meets the residents' supply. In contrast to previous studies on separate accounting versus formula apportionment refereed to in the introduction, we consider labor market imperfections which prevent the market to attain an equilibrium. To keep the analysis as simple as possible, it is assumed that the imperfections cause wage rate rigidities which, in turn, fix the wage rate at some level above the equilibrium wage rate. Hence, labor supply exceeds labor demand and some residents are involuntarily unemployed. Since labor supply is normalized to one, both the number of unemployed individuals and the unemployment rate in country $i$ equals $1-\ell_{i}$. The employment rate is $\ell_{i}$.

Such a fixed wage approach to unemployment is also used by Ogawa et al. (2006), for instance. The great advantage is that it keeps the analysis tractable. The fixed wage rate assumption might be seen restrictive. However, in our setting it is equivalent to an efficiency wage approach to unemployment used by e.g. Ogawa et al. (2004). 
Under such an approach, efficiency units of labor $E\left(w_{i}\right) \ell_{i}$ instead of labor $\ell_{i}$ enter the production function. The effort function $E$ is increasing in the wage rate which is endogenously chosen by the MNE. It can then be shown that under both separate accounting and formula apportionment the profit maximizing wage rate is determined by $w_{i} E^{\prime}\left(w_{i}\right) / E\left(w_{i}\right)=1$. Thus, as under our approach, the wage rate is fixed since it is influenced by the properties of the effort function only and independent of any policy instrument. In addition, our fixed wage assumption may be viewed as a short cut of the labor unions' influence which usually restricts the wage rate from below.

Governments. The government of country $i$ provides the local public good which is financed by the revenue from corporate income taxation. We formally introduce the public budget constraint in the next sections when the tax rules under separate accounting and formula apportionment are specified. The objective of the government is to maximize its inhabitants' Utilitarian welfare

$$
W^{i}=\left(1-\ell_{i}\right) U\left(x_{i}^{u}, g_{i}\right)+\ell_{i} U\left(x_{i}^{e}, g_{i}\right)
$$

that equals the sum of all residents' utility. Using the quasi-linear utility function (3) the welfare function (4) turns into

$$
W^{i}=\lambda\left(\theta_{i} \pi+w_{i} \ell_{i}+r \bar{k}_{i}\right)+V\left(g_{i}\right)
$$

As already mentioned above, by setting $\lambda=0$ in (5) we are able to investigate tax revenue maximization of the governments. Welfare in country $i$ then reduces to the utility the residents receive from the local public good and hence from tax revenue.

\section{Separate accounting}

Profit Maximization of the MNE. As benchmark we first briefly consider the case of separate accounting. Under this taxation principle, corporate income is taxed in the country where the MNE it declares. Denoting by $t_{i}$ country $i$ 's statutory tax rate, the MNE's total after-tax profit is given by

$$
\pi:=\left(1-t_{a}\right) \phi_{a}+\left(1-t_{b}\right) \phi_{b}-r(1-\rho)\left(k_{a}+k_{b}\right)-C(s) .
$$


The MNE maximizes the after-tax profit with respect to profit shifting $s$, investment $k_{i}$ and labor demand $\ell_{i}$ for $i \in\{a, b\}$. It takes as given the governments' tax rates $t_{a}$ and $t_{b}$. Indicating profit maximizing values under separate accounting by a tilde, the first-order conditions can be written as

$$
\begin{aligned}
\left(1-t_{i}\right)\left[F_{k}\left(\tilde{k}_{i}, \tilde{\ell}_{i}\right)-\rho r\right]-r(1-\rho) & =0, \\
F_{\ell}\left(\tilde{k}_{i}, \tilde{\ell}_{i}\right)-w_{i} & =0, \\
t_{a}-t_{b}-C^{\prime}(\tilde{s}) & =0,
\end{aligned}
$$

for $i \in\{a, b\}$. Equations (7a) and (7b) implicitly determine the profit maximizing capital and labor input as functions of the corporate income tax rates. Condition (7a) shows that for $\rho<1$ the MNE's investment decision is distorted by the tax since the marginal return to capital does not match the interest rate, i.e. $F_{k} \neq r$. In contrast, labor is fully deductible so that the labor demand decision of the MNE remains undistorted according to (7b). Equation (7c) determines the MNE's optimal profit shifting volume. If $t_{a}>t_{b}$, the marginal concealment cost will be positive and the firm transfers profit into country $b$. If $t_{a}>t_{b}$, shifting will be the other way round.

For the tax competition analysis, the comparative static effects of the countries' tax policy on the MNE's behavior are needed. We follow previous studies and pay attention to a symmetric situation in which both countries have the same tax rate $t_{a}=t_{b}=: t$. Differentiating (7a)-(7c) and applying the symmetry assumption yields ${ }^{3}$

$$
\begin{aligned}
\frac{\partial \tilde{k}_{i}}{\partial t_{i}} & =\frac{\left(F_{k}-\rho r\right) F_{\ell \ell}}{(1-t) H} \leq 0, \quad \frac{\partial \tilde{\ell}_{i}}{\partial t_{i}}=-\frac{\left(F_{k}-\rho r\right) F_{k \ell}}{(1-t) H} \leq 0 \\
\frac{\partial \tilde{k}_{i}}{\partial t_{j}} & =\frac{\partial \tilde{\ell}_{i}}{\partial t_{j}}=0 \\
\frac{\partial \tilde{s}}{\partial t_{a}} & =-\frac{\partial \tilde{s}}{\partial t_{b}}=\frac{1}{C^{\prime \prime}}>0,
\end{aligned}
$$

for $i, j \in\{a, b\}$ and $i \neq j$, with $H:=F_{k k} F_{\ell \ell}-F_{k \ell}^{2}>0$ and $F_{k}-\rho r=(1-\rho) r /(1-t) \geq 0$. For partial or no deductibility of capital cost $(\rho \in[0,1[)$, equation (8a) shows that increases in country $i$ 's tax rate reduce both capital and labor demand in country $i$. The effect on labor demand stems from the complementarity of capital and labor. Complementarity implies that a tax rate increase in country $i$ raises unemployment

\footnotetext{
${ }^{3}$ It is important to first differentiate and then apply the symmetry property since otherwise some effects go lost. We apply this procedure throughout the paper without mentioning it all the time.
} 
in country $i$. If capital is fully deductible $(\rho=1)$, the first-order condition (7a) will simplify to $F_{k}-r=0$. In this case, both investment and employment are independent of tax rates according to (8a). Due to the separate accounting principle, it is clear that tax increases in country $i$ do not influence investment and employment in country $j$. This is proven by $(8 \mathrm{~b})$. Finally, (8c) shows that an increase in country $i$ 's tax rate will induce the MNE to shift more profit into country $j$ if country $i$ 's tax rate lies above that of country $j$ or to reduce profit shifting to country $i$ if country $i$ 's tax rate falls short of country j's.

Tax Competition. Under separate accounting, country $i$ 's budget constraint reads

$$
g_{i}=t_{i} \phi_{i}
$$

It equates tax revenue with the expenditure for the public good. Country $i$ 's government chooses the tax rate $t_{i}$ in order to maximize (5) subject to (9). In doing so, it takes as given country $j$ 's tax rate $t_{j}$ and anticipates the MNE's behavior represented by $(7 \mathrm{a})-(7 \mathrm{c})$ and $(8 \mathrm{a})-(8 \mathrm{c})$. The first-order condition $\partial W^{i} / \partial t_{i}=0$ determines country $i$ 's reaction function, i.e. its best response to country $j$ 's tax rate.

As already mentioned above, we focus on a symmetric Nash equilibrium with equilibrium tax rates $\tilde{t}_{a}=\tilde{t}_{b}=: \tilde{t}$. Symmetry requires that the fixed wage rate is equal in both countries and the residents of both countries own the same share of the MNE, i.e. $w_{a}=w_{b}=: w$ and $\theta_{a}=\theta_{b}=: \theta$. Due to (1), (7a) and (7b) the MNE then realizes the same investment, labor demand and tax base in both countries, i.e. $\tilde{k}_{a}=\tilde{k}_{b}=: \tilde{k}$, $\tilde{\ell}_{a}=\tilde{\ell}_{b}=: \tilde{\ell}$ and $\phi_{a}=\phi_{b}=: \phi$. Our main interest is to assess the efficiency properties of the equilibrium tax rates. This can be done by investigating the fiscal externalities which are reflected by the cross effects of the tax rates on welfare, i.e. the effect of country $i$ 's tax rate on welfare in country $j$. A positive (negative) fiscal externality implies inefficient undertaxation (overtaxation). We report on the effect of $t_{b}$ on $W^{a}$ only because the symmetry assumption ensures that the effect of $t_{a}$ on $W^{b}$ is totally analogous. Differentiating (5) and taking into account (1), (8b) and (9), we obtain

$$
\frac{\partial W^{a}}{\partial t_{b}}=\lambda \theta \frac{\partial \pi}{\partial t_{b}}-\tilde{t} V^{\prime}(\cdot) \frac{\partial \tilde{s}}{\partial t_{b}} .
$$

There are two cross effects of country b's tax rate on country a's welfare. First, increasing $t_{b}$ reduces the MNE's after-tax profit and, thus, profit income of country $a$ 's 
residents. This income externality is represented by the first term on the RHS of (10). It is negative since the envelope theorem implies $\lambda \theta \partial \pi / \partial t_{b}=-\lambda \theta \phi<0$. Second, if country $b$ raises its tax rate, profit will be shifted from country $b$ to country $a$ with the consequence that the tax revenue and the quantity of the public good in country $a$ go up. This profit shifting externality is reflected by the second term on the RHS of (10). It is positive due to (8c). Taking both cross effects together we see that the sign of the total externality is ambiguous leaving it unclear whether the equilibrium tax rate is inefficiently low or high. However, for $\lambda=0$ the income externality disappears and the profit shifting externality implies inefficient undertaxation. Our results are summarized in

Proposition 1. Suppose the tax competition game under separate accounting attains a symmetric Nash equilibrium with $\tilde{t}_{a}=\tilde{t}_{b}=: \tilde{t}$. If governments maximize tax revenue $(\lambda=0)$, the equilibrium tax rate $\tilde{t}$ will be inefficiently low. Under welfare maximization $(\lambda>0)$, in contrast, the equilibrium tax rate $\tilde{t}$ may be inefficiently low or high.

These insights coincide with those of previous studies refereed to in the introduction. Proposition 1 shows that the results under separate accounting with perfect labor markets are qualitatively robust to introducing labor market imperfections. Unemployment itself does not create a fiscal externality under separate accounting.

\section{Formula Apportionment}

Profit Maximization of the MNE. Under formula apportionment, tax bases are consolidated and then distributed to the two countries according to a certain formula. In practice, the formula usually employs three apportionment factors in convex combinations: the capital, sales and payroll shares of the MNE in the respective country. Denoting by $\gamma, \sigma$ and $\varphi$ the weights these factors receive in the formula, the share of the consolidated tax base that is assigned to country a equals

$$
A\left(k_{a}, k_{b}, \ell_{a}, \ell_{b}\right)=\gamma \frac{k_{a}}{k_{a}+k_{b}}+\sigma \frac{F\left(k_{a}, \ell_{a}\right)}{F\left(k_{a}, \ell_{a}\right)+F\left(k_{b}, \ell_{b}\right)}+\varphi \frac{w_{a} \ell_{a}}{w_{a} \ell_{a}+w_{b} \ell_{b}},
$$

with $(\gamma, \sigma, \varphi) \in S$ where $S:=\left\{(\gamma, \sigma, \varphi) \mid(\gamma, \sigma, \varphi) \in[0,1]^{3}\right.$ and $\left.\gamma+\sigma+\varphi=1\right\}$ denotes the set of all feasible weights. The share $1-A(\cdot)$ of the consolidated tax base remains for 
country $b$. The MNE's tax burden in the countries $a$ and $b$ is given by $t_{a} A(\cdot)\left(\phi_{a}+\phi_{b}\right)$ and $t_{b}[1-A(\cdot)]\left(\phi_{a}+\phi_{b}\right)$, respectively. The MNE's total after-tax profit under formula apportionment can then be written as

$$
\pi=(1-\tau)\left(\phi_{a}+\phi_{b}\right)-r(1-\rho)\left(k_{a}+k_{b}\right)-C(s)
$$

where

$$
\tau=t_{a} A\left(k_{a}, k_{b}, \ell_{a}, \ell_{b}\right)+t_{b}\left[1-A\left(k_{a}, k_{b}, \ell_{a}, \ell_{b}\right)\right]
$$

is the effective tax rate the MNE faces in country $a$ and $b$. This effective tax rate equals the average of the national corporate income tax rates weighted by the shares of the consolidated tax base allocated to the two countries.

The MNE maximizes after-tax profit (12) with respect to capital, labor and profit shifting taking into account (1), (11) and (13). Indicating profit maximizing values under formula apportionment by a hat, the first-order conditions are given by

$$
\begin{aligned}
-\left(t_{a}-t_{b}\right) A_{k_{i}}(\cdot)\left(\phi_{a}+\phi_{b}\right)+(1-\tau)\left[F_{k}\left(\hat{k}_{i}, \hat{\ell}_{i}\right)-\rho r\right]-r(1-\rho) & =0 \\
-\left(t_{a}-t_{b}\right) A_{\ell_{i}}(\cdot)\left(\phi_{a}+\phi_{b}\right)+(1-\tau)\left[F_{\ell}\left(\hat{k}_{i}, \hat{\ell}_{i}\right)-w_{i}\right] & =0 \\
C^{\prime}(\hat{s}) & =0
\end{aligned}
$$

for $i \in\{a, b\}$. The conditions (14a)-(14c) have the usual interpretation. From (14c) we infer that for all feasible formulas the MNE does not face an incentive for profit shifting $(\hat{s}=0)$ since the tax base is consolidated. Similar to separate accounting, (14a) and (14b) contain the marginal return to capital and labor and the respective factor cost. But there is now an additional term that reflects the MNE's formula manipulation incentive. For a nonzero tax rate differential $t_{a}-t_{b}$ the MNE invests more and demands more labor in the country with the lower tax rate since this gives the lower tax rate a higher weight in the calculation of the effective tax rate and, thus, reduces the total tax liability. This effect is also derived in previous studies on formula apportionment.

For the tax competition analysis under formula apportionment, we need the comparative static effects of tax rate changes on the MNE's investment and labor decisions. We again focus on a symmetric solution with equal tax rates. We then have $t_{a}=t_{b}=\tau=: t, \hat{k}_{a}=\hat{k}_{b}=: \hat{k}, \hat{\ell}_{a}=\hat{\ell}_{b}=: \hat{\ell}, \phi_{a}=\phi_{b}=: \phi$ and $A(\cdot)=1 / 2$. Moreover, 
using the symmetry assumption the partial derivatives of the function $A$ simplify to

$$
A_{k_{a}}=-A_{k_{b}}=\frac{\gamma}{4 \hat{k}}+\frac{\sigma F_{k}}{4 F}, \quad A_{\ell_{a}}=-A_{\ell_{b}}=\frac{\varphi}{4 \hat{\ell}}+\frac{\sigma F_{\ell}}{4 F} .
$$

Total differentiating (14a) and (14b), the Appendix proves

$$
\begin{aligned}
& \frac{\partial \hat{k}_{i}}{\partial t_{i}}=\frac{1}{2(1-t) H}\left[\left(F_{k}-\rho r\right) F_{\ell \ell}+\phi\left(\frac{\gamma F_{\ell \ell}}{\hat{k}}+\frac{\sigma\left(F_{k} F_{\ell \ell}-F_{\ell} F_{k \ell}\right)}{F}-\frac{\varphi F_{k \ell}}{\hat{\ell}}\right)\right]<0, \\
& \frac{\partial \hat{k}_{j}}{\partial t_{i}}=\frac{1}{2(1-t) H}\left[\left(F_{k}-\rho r\right) F_{\ell \ell}-\phi\left(\frac{\gamma F_{\ell \ell}}{\hat{k}}+\frac{\sigma\left(F_{k} F_{\ell \ell}-F_{\ell} F_{k \ell}\right)}{F}-\frac{\varphi F_{k \ell}}{\hat{\ell}}\right)\right] \lesseqgtr 0, \quad(16 b) \\
& \frac{\partial \hat{\ell}_{i}}{\partial t_{i}}=\frac{1}{2(1-t) H}\left[-\left(F_{k}-\rho r\right) F_{k \ell}-\phi\left(\frac{\gamma F_{k \ell}}{\hat{k}}+\frac{\sigma\left(F_{k} F_{k \ell}-F_{\ell} F_{k k}\right)}{F}-\frac{\varphi F_{k k}}{\hat{\ell}}\right)\right]<0,\left(16{ }^{\prime}\right. \\
& \frac{\partial \hat{\ell}_{j}}{\partial t_{i}}=\frac{1}{2(1-t) H}\left[-\left(F_{k}-\rho r\right) F_{k \ell}+\phi\left(\frac{\gamma F_{k \ell}}{\hat{k}}+\frac{\sigma\left(F_{k} F_{k \ell}-F_{\ell} F_{k k}\right)}{F}-\frac{\varphi F_{k k}}{\hat{\ell}}\right)\right] \lesseqgtr 0,(16) \\
& \frac{\partial\left(\hat{k}_{a}+\hat{k}_{b}\right)}{\partial t_{i}}=\frac{\left(F_{k}-\rho r\right) F_{\ell \ell}}{(1-t) H} \leq 0, \quad \frac{\partial\left(\hat{\ell}_{a}+\hat{\ell}_{b}\right)}{\partial t_{i}}=-\frac{\left(F_{k}-\rho r\right) F_{k \ell}}{(1-t) H} \leq 0
\end{aligned}
$$

with $i \in\{a, b\}, i \neq j$, and $F_{k}-\rho r=r(1-\rho) /(1-t) \geq 0$ according to (14a) and the symmetry property. The comparative static effects of country $i$ 's tax rate in (16a)(16d) can be decomposed into two partial effects. The first is a tax base effect reflected by the terms containing $F_{k}-\rho r$. Under no or partial deductibility of capital cost ( $\rho \in[0,1[$ ), increasing country $i$ 's tax rate raises the MNE's effective tax burden and thus induces the MNE to reduce the tax base by lowering capital and labor demand in both countries. Even though labor cost is fully deductible, the tax base effect is also present at labor since labor is complementary to capital. The tax base effect emerges in both countries since tax bases are consolidated and taxed at the effective tax rate. Under full deductibility of capital cost, the tax base effect disappears since for $\rho=1$ it holds $F_{k}-\rho r=r(1-\rho) /(1-t)=0$. In this case, there is no distortion of capital and labor demand working through the tax base. The second partial effect of country $i$ 's tax rate is based on the above-mentioned incentive of the MNE to manipulate the apportionment formula. If country $i$ increases its tax rate, the MNE will reallocate capital and labor from country $i$ to country $j$. This formula effect is captured by the terms containing the formula weights $\gamma, \sigma$ and $\varphi$. It is a pure reallocation effect since in (16a) and (16b) and in (16c) and (16d) it is equal in size but opposite in sign. Hence, the formula effect does not play a role for the impact of country $i$ 's tax rate on the 
MNE's total investment and total labor demand as shown by (16e). In the aggregate, only the tax base effect remains with the consequence that the MNE reduces both total investment and total labor demand as reaction upon an increase in country $i$ 's tax rate.

With respect to unemployment, the comparative static results show that country $i$ 's tax rate has a negative effect on employment in country $i$ and on total employment in both countries. This is similar to the case of separate accounting, even though the size of the effects may differ under the two tax principles. In contrast to separate accounting, however, under formula apportionment country $i$ 's tax rate also influences unemployment in country $j$ according to the cross effect (16d). In general, the sign of this effect is ambiguous and depends on the relative size of the tax base effect and the formula effect. Hence, we cannot exclude that an increase in country $i$ 's tax rate raises unemployment in country $i$. However, it is straightforward to prove that for a Cobb-Douglas production function $F\left(k_{i}, \ell_{i}\right)=k_{i}^{\alpha} \ell_{i}^{\beta}$ with $\left.\alpha+\beta \in\right] 0,1[$ the formula effect always outweighs the tax base effect and the total effect of country $i$ 's tax rate on labor demand in country $j$ is positive. More specific, denoting by $\left.\left(\partial \hat{\ell}_{j} / \partial t_{i}\right)\right|_{(\gamma, \sigma, \varphi)}$ the cross effect if the formula weights are given by $\gamma, \sigma$ and $\varphi$, the Appendix shows that for given tax rate $t$ the Cobb-Douglas production function implies

$$
\left.\min _{(\gamma, \sigma, \varphi) \in S} \frac{\partial \hat{\ell}_{j}}{\partial t_{i}}\right|_{(\gamma, \sigma, \varphi)}=\left.\frac{\partial \hat{\ell}_{j}}{\partial t_{i}}\right|_{(\hat{\gamma}, \hat{\sigma}, 0)}>0 \quad \text { for all } \hat{\gamma}, \hat{\sigma} \in[0,1] \quad \text { and } \hat{\gamma}+\hat{\sigma}=1 .
$$

Equation (17) provides two insights. First, for a Cobb-Douglas production function an increase in country $i$ 's tax rate always reduces unemployment in country $j$. Second, the effect is the smallest whenever the apportionment formula does not contain a payroll factor. This is plausible in light of the analysis of McLure (1980). He argues that the formula transforms the corporate income tax into a tax or subsidy on the apportionment factors. Hence, without a payroll factor in the formula the tax burden on labor is the smallest and, thus, the MNE's incentive to reallocate labor demand from country $i$ to country $j$ as a reaction on a tax rate increase in country $i$ is the weakest.

Tax Competition. Under formula apportionment, the fiscal budget of country $a$ and $b$, respectively, satisfies the constraint

$$
\begin{aligned}
g_{a} & =t_{a} A\left(\hat{k}_{a}, \hat{k}_{b}, \hat{\ell}_{a}, \hat{\ell}_{b}\right)\left(\phi_{a}+\phi_{b}\right), \\
g_{b} & =t_{b}\left[1-A\left(\hat{k}_{a}, \hat{k}_{b}, \hat{\ell}_{a}, \hat{\ell}_{b}\right)\right]\left(\phi_{a}+\phi_{b}\right),
\end{aligned}
$$


where capital and labor depend on the tax rates via (16a)-(16d). The countries are again engaged in tax competition and set the tax rates such that welfare (5) is maximized subject to the budget constraints (18a) and (18b), respectively. In doing so, they take as given the tax rate of the respective other country. The Nash equilibrium of the tax competition game is constituted by $\partial W^{i} / \partial t_{i}=0$ for $i \in\{a, b\}$.

To study the efficiency properties of the tax rates in the Nash equilibrium we restrict our attention again to symmetric equilibria with tax rates $\hat{t}_{a}=\hat{t}_{b}=\tau=: \hat{t}$ and all the implications already mentioned in the previous paragraph. The fiscal externalities of country $b$ 's tax rate on country $a$ 's welfare are then reflected by

$$
\frac{\partial W^{a}}{\partial t_{b}}=\mathrm{IE}+\mathrm{TE}+\left.\mathrm{FE}\right|_{(\gamma, \sigma, \varphi)}+\left.\mathrm{UE}\right|_{(\gamma, \sigma, \varphi)},
$$

with

$$
\begin{aligned}
\mathrm{IE} & =-\lambda \theta \phi<0 \\
\mathrm{TE} & =\frac{\hat{t} V^{\prime}(\cdot)\left(F_{k}-\rho r\right)}{2} \frac{\partial\left(\hat{k}_{a}+\hat{k}_{b}\right)}{\partial t_{b}} \leq 0, \\
\left.\mathrm{FE}\right|_{(\gamma, \sigma, \varphi)} & =2 \hat{t} \phi V^{\prime}(\cdot)\left[A_{k_{a}} \frac{\partial\left(\hat{k}_{a}-\hat{k}_{b}\right)}{\partial t_{b}}+A_{\ell_{a}} \frac{\partial\left(\hat{\ell}_{a}-\hat{\ell}_{b}\right)}{\partial t_{b}}\right]>0, \\
\left.\mathrm{UE}\right|_{(\gamma, \sigma, \varphi)} & =\lambda w \frac{\partial \hat{\ell}_{a}}{\partial t_{b}},
\end{aligned}
$$

where the signs of (20a) and (20c) follow from (16a)-(16e). Due to the consolidation of tax bases the profit shifting externality disappears under formula apportionment. However, the income externality IE in (20a) remains and tends to inefficient undertaxation. In addition, several other externalities emerge under formula apportionment. The externalities in (20b) and (20c) go back to the tax base and formula effects derived in the comparative static analysis above. If country $b$ increases its tax rate, it does not take into account that country $a$ 's tax revenue declines due to a reduction in the MNE's consolidated tax base. This constitutes a negative tax base externality (TE) which points to inefficient overtaxation. Moreover, in raising its tax rate country $b$ ignores that country $a$ 's tax revenue increases since the MNE reallocates production factors from country $b$ to country $a$ so that a larger share of the consolidated tax base is taxed in country $a$. This represents a positive formula externality $\left(\mathrm{FE}_{(\gamma, \sigma, \varphi)}\right)$ and 
tends to inefficient undertaxation. In contrast to the tax base externality, the formula externality is a function of the formula weights since the MNE's incentive to reallocate production factors depends on the shape of the apportionment formula. Income, tax base and formula externalities are well known from previous studies, for example, Nielsen et al. (2004) and Riedel and Runkel (2006).

Our analysis reveals a fourth externality $\mathrm{UE}_{(\gamma, \sigma, \varphi)}$ in $(20 \mathrm{~d})$ that is caused by the existence of unemployment and therefore is absent in previous studies abstracting from labor market imperfections. The underlying intuition for this externality is straightforward: If country $b$ increases its tax rate, the MNE will change its labor demand not only in country $b$ but also in country $a$ as shown by (16d). Country $b$ 's tax rate thus influences unemployment and welfare in country $a$. The unemployment externality arises since in determining its tax policy country $b$ ignores this cross country effect. From the discussion in the previous section, we know that the effect of country $b$ 's tax rate on unemployment in country a may go in either direction. Hence, in general the unemployment externality may be positive or negative and it is not clear whether it tends to inefficiently low or high tax rates. Under a Cobb-Douglas production function, however, equation (17) states that an increase in country b's tax rate induces the MNE to demand more labor in country $a$. In this case, the unemployment externality is positive and tends to inefficient undertaxation.

As the sign of the unemployment externality may be different from that of the other externalities, it is important to investigate the interplay between the different externalities. We start with the comparison between unemployment and income externalities. For a general production function, it is not possible to get clear-cut results. But for the case of a Cobb-Douglas production function, the Appendix proves

Lemma 1. Suppose the production technology is Cobb-Douglas, i.e. $F\left(k_{i}, \ell_{i}\right)=k_{i}^{\alpha} \ell_{i}^{\beta}$ with $\alpha+\beta \in] 0,1[$. Then for given tax rate $\hat{t}$ it holds:

(i) $\left.\min _{(\gamma, \sigma, \varphi) \in S} \mathrm{UE}\right|_{(\gamma, \sigma, \varphi)}=\left.\mathrm{UE}\right|_{(\hat{\gamma}, \hat{\sigma}, 0)}>0$ for all $\hat{\gamma}, \hat{\sigma} \in[0,1]$ and $\hat{\gamma}+\hat{\sigma}=1$.

(ii) $\mathrm{IE}+\left.\mathrm{UE}\right|_{(\gamma, \sigma, \varphi)}>0$ for all $(\gamma, \sigma, \varphi) \in S$ if and only if

$$
\beta>\frac{(1-\hat{t})(1-\alpha)}{2-\hat{t}}+\frac{r(1-\rho) \hat{k}}{(2-\hat{t}) F(\cdot)} .
$$


Due to (17) the cross effect of one country's tax rate on the other country's employment will be the lowest if the formula does not contain a payroll factor. Since the unemployment externality is proportional to the cross effect, it is minimized for any non-payroll formula as shown by Lemma 1(i). But even for these formulas, Lemma 2(ii) shows that the unemployment externality will be large enough to compensate the income externality if the production elasticity of labor $\beta$ is sufficiently large such that condition (21) is satisfied. This is insofar plausible as the size of the unemployment externality is not only increasing in the formula weight placed on payroll but also in the production elasticity $\beta$. The higher this elasticity, the more productive is labor and the larger is the cross effect of one country's tax rate on labor demand and unemployment in the other country. It is then clear that for a high production elasticity of labor the positive unemployment externality overcompensates the negative income externality and the sum of both externalities points to inefficient undertaxation.

Inequality (21) will be satisfied, for example, if $\beta \geq(1-\alpha) / 2$ and the term $r(1-$ $\rho) \hat{k} /(2-\hat{t}) F$ is sufficiently low. The former condition is consistent with empirical evidence derived by Mankiw et al. (1992) and Nonneman and Vanhoudt (1996) who found $\alpha \in[0.3,0.35]$ and $\beta \in[0.35,0.45]$. Less clear is the size of the term $r(1-$ $\rho) \hat{k} /(2-\hat{t}) F$. It vanishes under full deductibility of capital cost $(\rho=1)$. For the more realistic case of partial deductibility $(\rho \in] 0,1[)$, the size of the term also depends on the equilibrium tax rate $\hat{t}$, investment $\hat{k}$ and output $F$. In the empirical calibration presented in the next section, the term may indeed be such that (21) is violated and the sum of income and unemployment externalities becomes negative. However, in such cases the unemployment externality will still be large enough so that the theoretical results which we now derive on the basis of Lemma 2(ii) remain valid.

To judge the overall efficiency of the equilibrium tax rate $\hat{t}$ both the tax base and formula externality have to be taken into account. These two externalities are opposite in sign leaving the sign of $\mathrm{TE}+\left.\mathrm{FE}\right|_{(\gamma, \sigma, \varphi)}$ indeterminate for general production functions. Restricting attention to the Cobb-Douglas technology the Appendix shows

Lemma 2. Suppose the production technology is Cobb-Douglas, i.e. $F\left(k_{i}, \ell_{i}\right)=k_{i}^{\alpha} \ell_{i}^{\beta}$ with $\alpha+\beta \in] 0,1[$. Then for given tax rate $\hat{t}$ it holds:

(i) $\left.\min _{(\gamma, \sigma, \varphi) \in S} \mathrm{FE}\right|_{(\gamma, \sigma, \varphi)}=\left.\mathrm{FE}\right|_{(0,1,0)}>0$ 
(ii) If capital cost is either fully deductible $(\rho=1)$ or not deductible at all $(\rho=0)$, then $\mathrm{TE}+\left.\mathrm{FE}\right|_{(\gamma, \sigma, \varphi)}>0$ for all $(\gamma, \sigma, \varphi) \in S$.

With a pure property or payroll formula, the MNE's incentive to manipulate the formula is quite strong since apportionment is targeted directly at the production factors. As a consequence, the formula externality is relatively large. In contrast, if apportionment uses the sales share only, then it will be directed at the production factors indirectly, namely via the production function. Due to the existence of a fixed factor, manipulating a pure sales formula is more difficult than manipulating other formulas. This is the reason why the formula externality is minimized under a pure sales formula as shown by Lemma 2(i). Nevertheless, Lemma 2(ii) states that at least for a very high or a very low deductibility of capital cost the formula externality is still large enough to overcompensate the negative tax base externality so that the sum of both externalities is positive and tends to inefficient undertaxation. This insight generalizes the analysis of Haufler (2006) who proves the same result in a model with no deductibility of capital cost and with capital as the sole production and apportionment factor.

With respect to the overall efficiency of the equilibrium tax rates under formula apportionment, Lemmas 1 and 2 immediately imply

Proposition 2. Suppose the tax competition game under formula apportionment attains a symmetric Nash equilibrium with $\hat{t}_{a}=\hat{t}_{b}=: \hat{t}$. Moreover, suppose the production technology is Cobb-Douglas, i.e. $F\left(k_{i}, \ell_{i}\right)=k_{i}^{\alpha} \ell_{i}^{\beta}$ with $\left.\alpha+\beta \in\right] 0,1[$, and capital cost is either fully deductible $(\rho=1)$ or not deductible at all $(\rho=0)$. If

(i) governments maximize tax revenues $(\lambda=0)$ or

(ii) the production elasticity of labor $\beta$ satisfies (21),

then $\hat{t}$ will be inefficiently low for all $(\gamma, \sigma, \varphi) \in S$.

Proposition 2 identifies sufficient conditions for the equilibrium tax rates under formula apportionment to be inefficiently low. According to Proposition 2(i), undertaxation occurs if governments maximize tax revenue. In this case, income and unemployment externalities are absent. The sum of the remaining tax base and formula externalities is positive under the conditions of Lemma 2(ii) and, thus, causes inefficiently low tax rates. For the case of welfare maximization, Proposition 2(ii) proves undertaxation if 
the production elasticity of labor is sufficiently large so that the sum of income and unemployment externalities is positive due to Lemma 1(i). It is worthwhile to point out the important role the unemployment externality plays for this result. While the sum of tax base and formula externalities is positive, the income externality has a negative sign. Without unemployment the income externality may therefore cause inefficient overtaxation. But taking into account labor market imperfections, the associated unemployment externality overcompensates the income externality and ensures that tax rates fall short of their efficient level. In other words, under the conditions of Proposition 2 overtaxation is possible without unemployment but not with unemployment.

Lemmas 1 and 2 show that the size of the unemployment and the formula externalities depends on the shape of the apportionment formulas. Hence, starting from the insight that the equilibrium tax rate under formula apportionment may be inefficient, it is natural to ask under which formula the tax rate comes closest to the efficient solution. To answer the question, it is useful to rank the equilibrium tax rate under the different formulas. In doing so, we need the first-order condition of the countries' welfare maximization. Maximizing (5) subject to (18b) and using (20a) - (20d) as well as $\partial \hat{\ell}_{b} / \partial \tau_{b}=-\partial \hat{\ell}_{a} / \partial t_{b}-\left(F_{k}-\rho r\right) F_{k \ell} /[(1-\hat{t}) H]$ from (16c) and (16d), the first-order condition for country $b$ 's welfare maximum can be written as

$$
\left.\frac{\partial W^{b}}{\partial t_{b}}\right|_{(\gamma, \sigma, \varphi)}=\phi V^{\prime}-\lambda w \frac{\left(F_{k}-\rho r\right) F_{k \ell}}{(1-\hat{t}) H}+\mathrm{IE}+\mathrm{TE}-\left.\mathrm{FE}\right|_{(\gamma, \sigma, \varphi)}-\left.\mathrm{UE}\right|_{(\gamma, \sigma, \varphi)}=0
$$

The first four terms in (22) are independent of the formula weights since in a symmetric equilibrium with equal tax rates neither investment nor labor demand depends on the formula weights according to (14a) and (14b). Comparing the last two terms for different formulas reveals which of the formulas implements the highest equilibrium tax rate. Lemma 1(i) and Lemma 2(i) state that under a Cobb-Douglas production technology both the formula externality $\left.\mathrm{FE}\right|_{(\gamma, \sigma, \varphi)}$ and the unemployment externality $\left.\mathrm{UE}\right|_{(\gamma, \sigma, \varphi)}$ are positive and minimized at the pure sales formula. Consequently, if the welfare function is assumed to be concave, we obtain ${ }^{4}$

Lemma 3. Suppose the tax competition game under formula apportionment attains a symmetric Nash equilibrium and the production technology is Cobb-Douglas, i.e.

\footnotetext{
${ }^{4}$ Note that Lemma 3 is quite general in the sense that it uses neither the conditions (i) and (ii) in Proposition 2 nor the assumption of no or full deductibility of capital cost.
} 
$F\left(k_{i}, \ell_{i}\right)=k_{i}^{\alpha} \ell_{i}^{\beta}$ with $\left.\alpha+\beta \in\right] 0,1[$. Then the equilibrium tax rate under the sales formula $(\gamma, \sigma, \varphi)=(0,1,0)$ is higher than under any other formula $(\gamma, \sigma, \varphi) \in S \backslash\{(0,1,0)\}$.

If the whole formula weight lies on capital, the countries possess a strong incentive for lowering the tax rates since in this case they try to attract more capital and increase welfare. The same is true if the whole weight is placed on payroll since then a decrease in the tax rate ceteris paribus reduces unemployment and increases welfare. From these two polar cases it is intuitively clear that the incentive for a race-to-the-bottom in corporate income taxation is the weakest under a pure sales formula as shown by Lemma 3. If the formula exclusively uses the sales factor, the incentive for lowering tax rates will be weakened since, in contrast to pure property or payroll formulas, the formula now contains a fixed element via the fixed production factor.

With the help of this insight about the absolute size of tax rates, we are now in the position to answer the question which apportionment formula generates the smallest distortion of corporate income taxation. Proposition 2 and Lemma 3 imply

Proposition 3. Suppose all assumptions of Proposition 2 are satisfied. Then the equilibrium tax rate comes closer to the efficient tax rate under the pure sales formula $(\gamma, \sigma, \varphi)=(0,1,0)$ than under any other formula $(\gamma, \sigma, \varphi) \in S \backslash\{(0,1,0)\}$.

Under the conditions of Proposition 2, we have inefficient undertaxation and from Lemma 3 we know that under the sales formula tax rates are the highest. It is therefore clear that the sales formula performs best among all feasible apportionment mechanisms. The sales formula ensures the best mix of the counteracting externalities. It ensures that the (positive) sum of the formula and tax base externalities is minimized and it generates an unemployment externality of ideal size. This means that the unemployment externality is strong enough to overcompensate the income externality, but not too strong to push the equilibrium tax rate far away from its efficient level.

\section{Calibration}

Our main finding in the previous section was that under formula apportionment the presence of unemployment generates a new fiscal externality which is responsible for inefficient undertaxation and that this undertaxation is the least severe under a pure 
sales formula. Unfortunately, in deriving this result the complexity of the model forced us to focus on the extreme cases of full or no deductibility of capital $\operatorname{cost}^{5}$ while realworld tax systems are usually characterized by partial deductibility. The result also heavily relies on condition (21) which ensures that the unemployment externality outweighs the income externality. Moreover, we did not yet conduct a comparison between separate accounting and formula apportionment since Propositions 1 and 2 show that such a comparison will definitely produce indeterminate results. For those reasons we now empirically calibrate the model to the EU-25 countries in order to check whether the results of our theoretical analysis will prevail when we further improve the relevance of our assumptions and whether a transition from separate accounting to formula apportionment is likely to be beneficial for the member countries of the EU.

In accordance with most real-world tax systems, capital cost is now assumed to be partially deductible. Instead of introducing a general deduction parameter $\rho$, we distinguish between the deduction of debt cost and depreciation allowances. We assume the MNE finances a share $\rho_{\varrho} \in[0,1]$ of its activities by debt and the interest rate is $\varrho$. In contrast to equity cost, debt cost $\rho_{\varrho} \varrho k_{i}$ can be deducted. Moreover, economic depreciation in the long-run is $\delta=1$ while we assume a share $\rho_{\delta}$ to be tax deductible. Our model is able to map the deduction of debt cost and depreciation allowances if we set $\rho r=\rho_{\varrho} \varrho+\rho_{\delta}$ and $r(1-\rho)=\varrho\left(1-\rho_{\varrho}\right)+1-\rho_{\delta}$ in all relevant equations. Desai et al. (2004) find $\rho_{\varrho} \approx 0.4$ and Devereux et al. (2002) estimate $\rho_{\delta} \approx 0.7$. A suitable value for $\varrho$ is 0.05 . Inserting these values in the above relations gives $\rho r=\rho_{\varrho} \varrho+\rho_{\delta}=0.72$ and $r(1-\rho)=\varrho\left(1-\rho_{\varrho}\right)+1-\rho_{\delta}=0.33$. Solving for $r$ and $\rho$, we obtain $r=1.05$ and $\rho=0.69$. Hence, for $r=1.05$ and $\rho=0.69$ our theoretical model analyzed in the previous sections captures both deduction of debt cost and depreciation allowances under empirically relevant parameter values.

The assumption of a Cobb-Douglas technology is retained in the calibration. We now explicitly include all three production factors, i.e. the production function now reads $F(k, \ell, q)=k^{\alpha} \ell^{\beta} q^{\nu}$ with $\left.\alpha, \beta, \nu \in\right] 0,1[$ and $\alpha+\beta+\nu=1$. In accordance with Mankiw et al. (1992) and Nonneman and Vanhoudt (1996), the production elasticities of capital and labor are $\alpha=0.3$ and $\beta=0.35 .{ }^{6}$ Then $\nu=0.35$ follows from the linear

\footnotetext{
${ }^{5}$ Most previous studied referred to in the introduction focus on these special cases, too.

${ }^{6}$ From the discussion of Lemma 1 we know that the condition $\beta \geq(1-\alpha) / 2$ together with a very high deductibility $\rho$ ensures that (21) is satisfied. As already mentioned, Mankiw et al. (1992) and
} 
homogeneity of $F$. The utility function of the local public good is specified as $V(g)=\kappa g$ where $\kappa$ can be interpreted as the marginal cost of public funds. In accordance with Kleven and Kreiner (2006), we choose $\kappa=1.325$. The residents of the two countries are supposed to own an equal share $\theta=0.5$ of the MNE. Finally, the concealment cost function is assumed to satisfy $C(s)=\zeta s^{2} / 2$. The parameter $\zeta$ together with $q$ and $w$ are used to calibrate the model. More specific, separate accounting is the prevailing taxation principle in the EU. Thus, we choose $\zeta, q$ and $w$ such that the tax rate, tax revenue and unemployment rate under separate accounting match the EU-25 average data in 2004. These data are listed in Table 1.

- Table 1 here -

We set the parameters such that $\tilde{t}=0.274,1-\tilde{\ell}=0.091$ and $\tilde{t} \phi=9.855$. The result of the calibration is $\zeta=0.0265, q=21206.5$ and $w=29.8026$.

With these results we are now in the position to calculate the efficient solution ${ }^{7}$ and to simulate the effects of a transition from separate accounting to formula apportionment. The results are listed in Tables 2 and 3.

- Tables 2 and 3 here -

Table 2 provides the insight that the equilibrium under separate accounting is characterized by inefficient overtaxation. For the 'average' European country, the corporate income tax rate lies 13 percentage points and the tax revenue over 4 billion euro above their efficient levels. As a consequence, under separate accounting unemployment is by 4.5 percentage points too high and welfare lies below its efficient level. The list of externalities in Table 3 shows that the reason for overtaxation is the large income externality which dominates the profit shifting externality. These insights are consistent with empirical findings. For example, Huizinga and Nicodème (2006) empirically investigate the extent of tax exporting among European countries. They find economNonneman and Vanhoudt (1996) obtain $\alpha \in[0.3,0.35]$ and $\beta \in[0.35,0.45]$. We deliberately set $\alpha$ and $\beta$ equal to the lower bounds of these intervals since $\beta \geq(1-\alpha) / 2$ then just holds as equality. For all other combinations of $\alpha$ and $\beta$ the strict inequality sign applies. Hence, by setting $\alpha=0.3$ and $\beta=0.35$ we choose the most unfavorable condition for our theoretical results to remain true.

${ }^{7}$ The efficient solution is obtained by maximizing total welfare from both countries, i.e. $W^{a}+W^{b}$. Details on the calculations can be obtained upon request. 
ically significant tax exporting effects and argue that the resulting income externality explains the absence of a race-to-the-bottom in corporate income taxation.

The introduction of formula apportionment is simulated for several formulas. Beside the pure formulas already considered in the theoretical analysis, we also include the so-called Massachusetts formula (equal weight on all three apportionment factors) and the double sales formula. ${ }^{8}$ Both are extensively used in the US apportionment system. From the results in Table 2 we infer that under each formula tax rates are inefficiently low and that the tax rate under a pure sales formula comes closest to the efficient solution. These are exactly the same conclusions as in our theoretical analysis, but here derived for the more realistic case of partial deductibility. Note also that we obtain the same results as in the theoretical model despite the fact that condition (21) may be violated. For example, under a pure property or a pure sales formula the income externality is absolutely larger than the unemployment externality. Due to Lemma 1(ii) this can happen only if (21) does not hold. Nevertheless, even in such cases the unemployment externality is strong enough to take away a large part of the income externality. As the tax base and the formula externalities are always relatively low, the unemployment externality is therefore the main reason for undertaxation.

In comparison to separate accounting, formula apportionment reduces corporate tax rates. This tax cut leads to a decline in tax revenue which ranges from about 5 billion euro under a pure sales formula to roughly 10 billion euro under a pure payroll formula (where corporate income taxation completely vanishes). However, the reduction in tax rates is also accompanied by a decline in unemployment. For example, under a pure sales formula the average unemployment rate is more than halved from $9.1 \%$ to $3.9 \%$. This positive employment effect is the reason why undertaxation under formula apportionment is less severe in terms of welfare than overtaxation under separate accounting. The introduction of formula apportionment exerts a positive effect on welfare and the welfare increase is the highest under a pure sales formula since the distortion

\footnotetext{
${ }^{8}$ All results of our theoretical analysis have been derived under the (not explicitly stated) assumption of an interior solution with respect to the corporate tax rate. In contrast, the simulation of formula apportionment with a pure payroll formula yields the corner solution of a zero tax rate. Of course, we may here also ensure an interior solution by allowing for negative tax rates. But a subsidy which is proportional to positive profit of MNEs seems to be quite unrealistic.
} 
of the corporate tax rates is here the smallest. ${ }^{9}$ Based on our calculations a transition from separate accounting to formula apportionment therefore seems to be an attractive policy option for the EU, especially if apportionment employs the MNEs' sales shares.

\section{Conclusion}

This paper analyzed corporate income taxation of MNEs in the presence of labor market imperfections. We used a two-country model with multinational activities and a fixed wage approach to unemployment. While unemployment does not cause a fiscal externality under separate accounting, under formula apportionment we identified an unemployment externality in corporate income taxation. With a Cobb-Douglas production technology this externality is positive since an increase in one country's tax rate then improves employment in the other country via a tax base and a formula effect. As intuitively plausible, we show that the unemployment externality is minimized whenever the apportionment formula does not contain a payroll factor and that it tends to outweigh other externalities such that tax rates become inefficiently low. The distortions are minimized under a pure sales formula. With the help of an empirical calibration of the model to EU-25, we show that the transition from separate accounting to formula apportionment reduces tax rates and unemployment and increases welfare.

There are several interesting extensions of our analysis. For example, in the fixed wage approach to unemployment the corporate tax policy does not have an effect on wages. While this is consistent with an efficiency wage approach to unemployment, repercussions of the tax policy on wages may appear in a wage bargaining approach to unemployment. In such a setting, it will be interesting to investigate whether corporate income taxation exerts fiscal externalities via the wage rates and, if so, which implications such externalities have for the efficiency of the corporate income tax policy. Moreover, in our analysis we followed the previous literature and assumed per-

\footnotetext{
${ }^{9}$ From the figures in Table 2 one may think that the welfare increases are negligible. However, we view welfare as an ordinal measure of the residents' well-being so that it provides information about the ranking of the different regimes only. Put differently, without changing any of the other results welfare in each country could always be multiplied by a huge constant so that the absolute differences between welfare under separate accounting and formula apportionment become large. For that reason we refrain from interpreting the size of the welfare differences.
} 
fectly identical countries and a symmetric equilibrium of the tax competition game. It might be an interesting task to investigate the implications of country asymmetries for the fiscal externalities arising under separate accounting and formula apportionment. However, before investigating these implications in the presence of unemployment it is important to understand them in the absence of unemployment. To the best of our knowledge, such a study is missing in the literature so far and we therefore leave the analysis of corporate income taxation and unemployment in a model with asymmetric countries for future research, too.

\section{Appendix}

Derivation of (16a)-(16e). Total differentiating (14a) and (14b) and then applying the symmetry property yields

$$
\begin{aligned}
-2 \phi A_{k_{i}}\left(\mathrm{~d} t_{a}-\mathrm{d} t_{b}\right)-\left(F_{k}-r \rho\right) \mathrm{d} \tau+(1-t)\left(F_{k k} \mathrm{~d} \hat{k}_{i}+F_{k \ell} \mathrm{d} \hat{\ell}_{i}\right) & =0 \\
-2 \phi A_{\ell_{i}}\left(\mathrm{~d} t_{a}-\mathrm{d} t_{b}\right)+(1-t)\left(F_{\ell k} \mathrm{~d} \hat{k}_{i}+F_{\ell \ell} \mathrm{d} \hat{\ell}_{i}\right) & =0 .
\end{aligned}
$$

From (13) and the symmetry property we obtain $\mathrm{d} \tau=A \mathrm{~d} t_{a}+(1-A) \mathrm{d} t_{b}$. Equations (23a) and $(23 \mathrm{~b})$ can then be rearranged to

$$
(1-t) M\left(\begin{array}{c}
\mathrm{d} \hat{k}_{i} \\
\mathrm{~d} \hat{\ell}_{i}
\end{array}\right)=\left(\begin{array}{c}
2 \phi A_{k_{i}}\left(\mathrm{~d} t_{a}-\mathrm{d} t_{b}\right)+\left(F_{k}-r \rho\right)\left[A \mathrm{~d} t_{a}+(1-A) \mathrm{d} t_{b}\right] \\
2 \phi A_{\ell_{i}}\left(\mathrm{~d} t_{a}-\mathrm{d} t_{b}\right)
\end{array}\right)
$$

with

$$
M:=\left(\begin{array}{cc}
F_{k k} & F_{k \ell} \\
F_{k \ell} & F_{\ell \ell}
\end{array}\right)
$$

Solving the matrix equation (24) by using Cramer's rule yields

$$
\begin{aligned}
(1-t)|M| \cdot \mathrm{d} \hat{k}_{i}= & {\left[2 \phi A_{k_{i}}\left(\mathrm{~d} t_{a}-\mathrm{d} t_{b}\right)+\left(F_{k}-r \rho\right)\left[A \mathrm{~d} t_{a}+(1-A) \mathrm{d} t_{b}\right]\right] F_{\ell \ell} } \\
& -2 \phi A_{\ell_{i}} F_{k \ell}\left(\mathrm{d} t_{a}-\mathrm{d} t_{b}\right) \\
(1-t)|M| \cdot \mathrm{d} \hat{\ell}_{i}= & -\left[2 \phi A_{k_{i}}\left(\mathrm{~d} t_{a}-\mathrm{d} t_{b}\right)+\left(F_{k}-r \rho\right)\left[A \mathrm{~d} t_{a}+(1-A) \mathrm{d} t_{b}\right]\right] F_{k \ell} \\
& +2 \phi A_{\ell_{i}} F_{k k}\left(\mathrm{~d} t_{a}-\mathrm{d} t_{b}\right),
\end{aligned}
$$

where $|M| \equiv H:=F_{k k} F_{\ell \ell}-F_{k \ell}^{2}>0$. Finally, using (15) we obtain after some rearrangement of terms (16a)-(16e). 
Derivation of (17). Note that the derivatives of the Cobb-Douglas function are $F_{k}=\alpha \hat{k}^{\alpha-1} \hat{\ell}^{\beta}, F_{\ell}=\beta \hat{k}^{\alpha} \hat{\ell}^{\beta-1}, F_{k \ell}=\alpha \beta \hat{k}^{\alpha-1} \hat{\ell}^{\beta-1}, F_{k k}=\alpha(\alpha-1) \hat{k}^{\alpha-2} \hat{\ell}^{\beta}$ and $F_{\ell \ell}=$ $\beta(\beta-1) \hat{k}^{\alpha} \hat{\ell}^{\beta-2}$. We now first show that in a symmetric situation with given tax rate $t$ the cross effect in (16d) under a pure capital formula is the same as under a pure sales formula. This is simply proven by taking into account that $H,\left(F_{k}-\rho r\right) F_{k \ell}$ and $\phi$ are independent of the formula weights and that the Cobb-Douglas function implies

$$
\frac{F_{k} F_{k \ell}-F_{\ell} F_{k k}}{F}=\frac{F_{k \ell}}{k}=\alpha \beta k^{\alpha-2} \ell^{\beta-1} .
$$

Next, we show that under a pure capital or, equivalently, a pure sales formula (16d) is positive. Focusing on the pure capital formula this is proven by

$$
\left(F_{k}-\rho r\right) F_{k \ell}-\phi \frac{F_{k \ell}}{k}=F_{k \ell}\left(F_{k}-\frac{F}{k}+\frac{\ell F_{\ell}}{k}\right)=-k^{2 \alpha-2} \ell^{2 \beta-1} \alpha \beta(1-\alpha-\beta)<0
$$

and $-1 /[2(1-t) H]<0$. Finally, we show that the cross effect $(16 \mathrm{~d})$ is minimized whenever the weight on the payroll factor is set equal to zero. The idea of the proof is to start with a formula that does not contain the payroll factor and then to increase the weight placed on payroll and to simultaneously reduce the weight placed on the other factors. If this increases the cross effect (16d) for all possible combinations of the formula weights, (17) is established. Since all convex combinations of the capital and sales factors with $\gamma+\sigma=1$ yield the same cross effect, we are free to fix one weight of these factors and only vary the other. Fixing $\sigma$ then implies

$$
\begin{aligned}
\frac{\partial}{\partial \varphi}\left(\left.\frac{\partial \hat{\ell}_{j}}{\partial t_{i}}\right|_{(\gamma, \sigma, \varphi)}\right)-\frac{\partial}{\partial \gamma}\left(\left.\frac{\partial \hat{\ell}_{j}}{\partial t_{i}}\right|_{(\gamma, \sigma, \varphi)}\right) & =\frac{\phi}{2(1-t) H}\left(\frac{F_{k \ell}}{\hat{k}}-\frac{F_{k k}}{\hat{\ell}}\right) \\
& =\frac{\alpha(1-\alpha+\beta) \phi \hat{k}^{\alpha-2} \hat{\ell}^{\beta-1}}{2(1-t) H}>0 .
\end{aligned}
$$

Hence, increasing the weight on payroll always increases the cross effect (16d).

Proof of Lemma 1. Part (i) follows from (17) and the definition of $\left.\mathrm{UE}\right|_{(\gamma, \sigma, \varphi)}$ in (20d). Since $\left.\mathrm{UE}\right|_{(\gamma, \sigma, \varphi)}$ is positive and attains its minimum at $(\gamma, \sigma, \varphi)=(1,0,0)$, part (ii) can be proven by showing that IE $+\left.\mathrm{UE}\right|_{(1,0,0)}>0$ if and only if $(21)$ is satisfied. Note that we suppose $\theta=1 / 2$. It is clear that the result also holds for $\theta \in] 0,1 / 2[$ since 
IE is increasing in $\theta$. The sum of the two externalities can then be written as

$$
\begin{aligned}
\mathrm{IE}+\left.\mathrm{UE}\right|_{(1,0,0)} & =-\frac{\lambda \phi}{2}+\left.\lambda w \frac{\partial \hat{\ell}_{a}}{\partial t_{b}}\right|_{(1,0,0)} \\
& =-\frac{\lambda}{2(1-\hat{t}) H}\left[\phi(1-\hat{t}) H+F_{\ell} F_{k \ell}\left(F_{k}-\rho r-\frac{\phi}{\hat{k}}\right)\right] .
\end{aligned}
$$

Using $F_{\ell} F_{k \ell}\left(F_{k}-\rho r-\phi / \hat{k}\right)=-F_{\ell} F_{k \ell}\left(F / \hat{k}-\hat{\ell} F_{\ell} / \hat{k}-F_{k}\right)=-(1-\alpha-\beta) \alpha \beta^{2} \hat{k}^{2 \alpha-2} \hat{\ell}^{2 \beta-2} F$ and $H=F_{k k} F_{\ell \ell}-F_{\ell k}^{2}=\alpha \beta(1-\alpha-\beta) \hat{k}^{2 \alpha-2} \hat{\ell}^{2 \beta-2}$ yields

$$
\mathrm{IE}+\left.\mathrm{UE}\right|_{(1,0,0)}=\frac{\lambda}{2(1-\hat{t})}[\beta F-(1-\hat{t}) \phi] .
$$

Recalling that $\phi=F-\ell F_{\ell}-\rho r \hat{k}$ and $\rho r=F_{k}-r(1-\rho) /(1-\hat{t})$ from (14a) we get

$$
\mathrm{IE}+\left.\mathrm{UE}\right|_{(1,0,0)}=\frac{\lambda}{2(1-\hat{t})}[\beta F-(1-\hat{t})(1-\alpha-\beta) F-\hat{k} r(1-\rho)] .
$$

The sum of the investment and unemployment externalities will be positive if and only if the bracketed term in (28) is positive which is equivalent to (21).

Proof of Lemma 2. We first prove part (i). Inserting (16a)-(16d) into (20c) yields

$$
\begin{aligned}
\left.\mathrm{FE}\right|_{(\gamma, \sigma, \varphi)}= & \frac{\hat{t} \phi^{2} V^{\prime}}{2(1-\hat{t}) H}\left\{-\frac{\gamma^{2} F_{\ell \ell}}{\hat{k}^{2}}-\frac{\sigma^{2}\left(F_{k}^{2} F_{\ell \ell}-2 F_{k} F_{\ell} F_{k \ell}+F_{\ell}^{2} F_{k k}\right)}{F^{2}}-\frac{\varphi^{2} F_{k k}}{\hat{\ell}^{2}}\right. \\
& \left.+\frac{2 \gamma \varphi F_{k \ell}}{\hat{k} \hat{\ell}}-\frac{2 \gamma \sigma\left(F_{k} F_{\ell \ell}-F_{\ell} F_{k \ell}\right)}{\hat{k} F}-\frac{2 \sigma \varphi\left(F_{\ell} F_{k k}-F_{k} F_{k \ell}\right)}{\hat{\ell} F}\right\}>0 .
\end{aligned}
$$

Using the Cobb-Douglas specification in (29) gives

$$
\begin{aligned}
\left.\mathrm{FE}\right|_{(1,0,0)} & =\beta(1-\beta) \frac{\hat{t} \phi^{2} \hat{k}^{\alpha-2} \hat{\ell}^{\beta-2} V^{\prime}}{2(1-\hat{t}) H}, \\
\left.\mathrm{FE}\right|_{(0,1,0)} & =\alpha \beta(\alpha+\beta) \frac{\hat{t} \phi^{2} \hat{k}^{\alpha-2} \hat{\ell}^{\beta-2} V^{\prime}}{2(1-\hat{t}) H} \\
\left.\mathrm{FE}\right|_{(0,0,1)} & =\alpha(1-\alpha) \frac{\hat{t} \phi^{2} \hat{k}^{\alpha-2} \hat{\ell}^{\beta-2} V^{\prime}}{2(1-\hat{t}) H} .
\end{aligned}
$$

Observe that $\beta(1-\beta)>\alpha \beta(\alpha+\beta)$ is equivalent to $1-\beta-\alpha(\alpha+\beta)>0$ which in turn is satisfied due to $\alpha+\beta<1$. Similar, $\alpha(1-\alpha)>\alpha \beta(\alpha+\beta)$ since $1-\alpha-\beta(\alpha+\beta)>0$. Hence, (30a)-(30c) imply FE $\left.\right|_{(1,0,0)}>\left.\mathrm{FE}\right|_{(0,1,0)}$ and $\left.\mathrm{FE}\right|_{(0,0,1)}>\left.\mathrm{FE}\right|_{(0,1,0)}$, i.e. among the pure formulas the sales formula generates the lowest formula externality. To complete 
the proof of part (i), it remains to show that the sales formula generates a lower formula externality than any other formula with convex combinations of the apportionment factors. Similar to the proof of (17), this is done by starting at $(\gamma, \sigma, \varphi)=(0,1,0)$ and then decreasing $\sigma$ and simultaneously increasing $\gamma$ and/or $\varphi$. If this change leads to a higher formula externality and that holds for all feasible $(\gamma, \sigma, \varphi)$, part (i) is established. Differentiating (29), we obtain

$$
\begin{aligned}
& \frac{\left.\partial \mathrm{FE}\right|_{(\gamma, \sigma, \varphi)}}{\partial \gamma}=\frac{\hat{t} \phi^{2} V^{\prime}}{(1-\hat{t}) H}\left[-\frac{\gamma F_{\ell \ell}}{\hat{k}^{2}}+\frac{\varphi F_{k \ell}}{\hat{k} \hat{\ell}}-\frac{\sigma\left(F_{k} F_{\ell \ell}-F_{\ell} F_{k \ell}\right)}{\hat{k} F}\right] \text {, } \\
& \frac{\left.\partial \mathrm{FE}\right|_{(\gamma, \sigma, \varphi)}}{\partial \sigma}=\frac{\hat{t} \phi^{2} V^{\prime}}{(1-\hat{t}) H}\left[-\frac{\sigma\left(F_{k}^{2} F_{\ell \ell}-2 F_{k} F_{\ell} F_{k \ell}+F_{\ell}^{2} F_{k k}\right)}{F^{2}}\right. \\
& \left.-\frac{\gamma\left(F_{k} F_{\ell \ell}-F_{\ell} F_{k \ell}\right)}{\hat{k} F}-\frac{\varphi\left(F_{\ell} F_{k k}-F_{k} F_{k \ell}\right)}{\hat{\ell} F}\right], \\
& \frac{\left.\partial \mathrm{FE}\right|_{(\gamma, \sigma, \varphi)}}{\partial \varphi}=\frac{\hat{t} \phi^{2} V^{\prime}}{(1-\hat{t}) H}\left[-\frac{\varphi F_{k k}}{\hat{\ell}^{2}}+\frac{\gamma F_{k \ell}}{\hat{k} \hat{\ell}}-\frac{\sigma\left(F_{\ell} F_{k k}-F_{k} F_{k \ell}\right)}{\hat{\ell} F}\right] .
\end{aligned}
$$

Using the properties of the Cobb-Douglas function and calculating the effect of the above described changes in the formula weights on the formula externality yields

$$
\begin{aligned}
\frac{\left.\partial \mathrm{FE}\right|_{(\gamma, \sigma, \varphi)}}{\partial \gamma}- & \frac{\left.\partial \mathrm{FE}\right|_{(\gamma, \sigma, \varphi)}}{\partial \sigma}=\beta(1-\alpha-\beta)(\gamma+\alpha \sigma) \frac{\hat{t} \phi^{2} \hat{k}^{\alpha-2} \hat{\ell}^{\beta-2} V^{\prime}}{(1-\hat{t}) H}>0, \\
\frac{\left.\partial \mathrm{FE}\right|_{(\gamma, \sigma, \varphi)}}{\partial \varphi}- & \frac{\left.\partial \mathrm{FE}\right|_{(\gamma, \sigma, \varphi)}}{\partial \sigma}=\alpha(1-\alpha-\beta)(\varphi+\beta \sigma) \frac{\hat{t} \phi^{2} \hat{k}^{\alpha-2} \hat{\ell}^{\beta-2} V^{\prime}}{(1-\hat{t}) H}>0, \\
\frac{\left.\partial \mathrm{FE}\right|_{(\gamma, \sigma, \varphi)}}{\partial \gamma}- & \frac{\left.\partial \mathrm{FE}\right|_{(\gamma, \sigma, \varphi)}}{\partial \sigma}+\frac{\left.\partial \mathrm{FE}\right|_{(\gamma, \sigma, \varphi)}}{\partial \varphi}= \\
& {[\gamma(1-\beta) \beta+\sigma \alpha \beta(2-\alpha-\beta)+\varphi(1-\alpha) \alpha] \frac{\hat{t} \phi^{2} \hat{k}^{\alpha-2} \hat{\ell}^{\beta-2} V^{\prime}}{(1-\hat{t}) H}>0 . }
\end{aligned}
$$

Hence, all feasible changes in the formula increases the formula externality as required.

The proof of part (ii) is trivial for $\rho=1$ which implies TE $=0$. For $\rho=0$ the properties of the Cobb-Douglas function yield $\phi=F-\ell F_{\ell}=(1-\beta) k^{\alpha} \ell^{\beta}$ and after some rearrangements of terms we get

$$
\mathrm{TE}+\left.\mathrm{FE}\right|_{(0,1,0)}=\alpha \beta^{2}(1-\beta)(1-\alpha-\beta) \frac{\hat{t} \hat{k}^{3 \alpha-2} \hat{\ell}^{3 \beta-2} V^{\prime}}{2(1-\hat{t}) H}>0 .
$$

Since for all other formulas the formula externality is higher than for the pure sales formula, the sign of (33) is true not only for $(\gamma, \sigma, \varphi)=(0,1,0)$ but for all convex combinations of $\gamma, \sigma$ and $\varphi$. 


\section{References}

Clausing, K. (2003), 'Tax-Motivated Transfer Pricing and US Intrafirm Trade Prices', Journal of Public Economics 87, 2207-23.

Desai, M.A., Foley, F. and J.R. Hines (2004), 'A Multinational Perspective on Capital Structure Choice and Internal Capital Markets', The Journal of Finance 59(6), 2451-87.

Devereux, M., Griffith, R. and A. Klemm (2002), 'Corporate Income Tax Reforms and International Tax Competition', Economic Policy, 451-95.

Eggert, W. and G. Schjelderup (2003), 'Symmetric Tax Competition under Formula Apportionment', Journal of Public Economic Theory 5, 439-46.

European Commission (2001), 'Towards an Internal Market Without Tax Obstacles: A Strategy for Providing Companies with a Consolidated Corporate Tax Base for Their EU-Wide Activities', $\operatorname{COM}(2001), 582$ final (October 23).

Fuest, C. and B. Huber (1999), 'Tax Coordination and Unemployment', International Tax and Public Finance 6, 7-26.

Gabszewicz, J.J. and T. van Ypersele (1996), 'Social Protection and Political Competition', Journal of Public Economics 61, 193-208.

Gérard, M. (2005), 'Multijurisdictional Firms and Governments' Strategies under Alternative Tax Designs', CESifo Working Paper No. 1527, University of Munich.

Gérard, M. (2006), 'Reforming the Taxation of Multijurisdictional Enterprises in Europe, A Tentative Appraisal', CESifo Working Paper No. 1795, University of Munich.

Goolsbee, A. and E.L. Maydew (2000), 'Coveting Thy Neighbor's Manufacturing: The Dilemma of State Income Apportionment', Journal of Public Economics 75, 125-43.

Gordon, R.H. and J.D. Wilson (1986), 'An Examination of Multijurisdictional Corporate Income Taxation under Formula Apportionment', Econometrica 54, 1357-73.

Haufler, A. (2006), 'Die Besteuerung multinationaler Unternehmen' Munich Discussion Paper in Economics No. 2006-21, University of Munich.

Haufler, A. and G. Schjelderup (2000), 'Corporate Tax Systems and Cross Country Profit Shifting', Oxford Economic Papers 52, 306-25.

Hines, J.R. Jr. (1999), 'Lessons from Behavioral Responses to International Taxation', National Tax Journal 52, 305-22.

Huizinga, H. and G. Nicodème (2006), 'Foreign Ownership and Corporate Income Taxation: An Empirical Evaluation', European Economic Review 50, 1223-44.

Huizinga, H. and S.B. Nielsen (1997), 'Capital Income and Profits Taxation with Foreign Ownership of Firms', Journal of International Economics 42, 149-65. 
Kant, C. (1988), 'Endogenous Transfer Pricing and the Effects of Uncertain Regulation', Journal of International Economics 24, 147-57.

Kind, J.K., Midelfart, K.H. and G. Schjelderup (2005), 'Corporate Tax Systems, Multinational Enterprises, and Economic Integration, Journal of International Economics 65, 507-21.

Kleven, J.K. and C.T. Kreiner (2006), 'The Marginal Cost of Public Funds: Hours of Work Versus Labor Force Participation', Journal of Public Economics 90, 1955-73.

Lejour, A.M. and H.A. Verbon (1996), 'Capital Mobility, Wage Bargaining, and Social Insurance Policies in an Economic Union', International Tax and Public Finance 3, 495-513.

Mankiw, N.G., Romer, D. and D.N. Weil (1992), 'A Contribution to the Empirics of Economic Growth', Quarterly Journal of Economics 107, 407-37.

McLure, C.E. (1980), 'The State Corporate Income Tax: Lambs in Wolves' Clothing', in: Aaron, A.J. and M.J. Boskin (Eds.), The Economics of Taxation, Washington DC: The Brookings Institution, 327-36.

Nielsen, S.B., Raimondos-Møller, P. and G. Schjelderup (2003), 'Formula Apportionment and Transfer Pricing under Oligopolistic Competition', Journal of Public Economic Theory 5, 419-37.

Nielsen, S.B., Raimondos-Møller, P. and G. Schjelderup (2004), 'Company Taxation and Tax Spillovers: Separate Accounting versus Formula Apportionment', mimeo.

Nonneman, W. and P. Vanhoudt (1996), 'A Further Augmentation of the Solow Model and the Empirics of Economic Growth for OECD Countries', Quarterly Journal of Economics 111, 943-53.

Ogawa, H., Sato, Y. and T. Tamai (2004), 'Unemployment and Capital Tax Competition', mimeo.

Ogawa, H., Sato, Y. and T. Tamai (2006), 'A Note on Unemployment and Capital Tax Competition', Journal of Urban Economics 60, 350-56.

Pethig, R. and A. Wagener (2003), 'Profit Tax Competition and Formula Apportionment', CESifo Working Paper No. 1011, University of Munich.

Richter, W. and K. Schneider (2001), 'Taxing Mobile Capital with Imperfect Labor Markets', International Tax and Public Finance 8, 245-62.

Riedel, N. and M. Runkel (2006), 'Company Tax Reform with a Water's Edge', Journal of Public Economics, forthcoming.

Sørensen, P.B. (2004), 'Company Tax Reform in the European Union', International Tax and Public Finance 11, 91-115. 
Table 1: Unemployment and Corporate Income Taxation in EU-25 countries 2004

\begin{tabular}{|c|c|c|c|}
\hline country & $\begin{array}{r}\text { unemployment rate } \\
\text { (in percent) }\end{array}$ & $\begin{array}{r}\text { tax rate } \\
\text { (in percent) }\end{array}$ & $\begin{array}{r}\text { tax revenue } \\
\text { (in billion euro) }\end{array}$ \\
\hline Austria & 4.8 & 34.0 & 5.732 \\
\hline Belgium & 8.4 & 34.0 & 9.245 \\
\hline Cyprus & 4.7 & 15.0 & 0.549 \\
\hline Czech Republic & 8.3 & 28.0 & 3.999 \\
\hline Denmark & 5.5 & 30.0 & 6.263 \\
\hline Estonia & 9.7 & 26.0 & 0.161 \\
\hline Finland & 8.8 & 29.0 & 5.240 \\
\hline France & 9.6 & 35.4 & 39.765 \\
\hline Germany & 9.5 & 38.3 & 17.725 \\
\hline Greece & 10.5 & 35.0 & 5.556 \\
\hline Hungary & 6.1 & 17.7 & 1.786 \\
\hline Ireland & 4.5 & 12.5 & 5.335 \\
\hline Italy & 8.0 & 37.3 & 30.614 \\
\hline Latvia & 10.4 & 15.0 & 0.192 \\
\hline Lithuania & 11.4 & 15.0 & 0.338 \\
\hline Luxembourg & 5.1 & 30.4 & 2.137 \\
\hline Malta & 7.3 & 35.0 & 0.156 \\
\hline Netherlands & 4.6 & 34.5 & 16.266 \\
\hline Poland & 19.0 & 19.0 & 4.482 \\
\hline Portugal & 6.7 & 27.5 & 4.577 \\
\hline Slovak Rebublic & 18.2 & 19.0 & 0.948 \\
\hline Slovenia & 6.3 & 25.0 & 0.514 \\
\hline Spain & 10.7 & 35.0 & 27.631 \\
\hline Sweden & 6.3 & 28.0 & 8.442 \\
\hline United Kingdom & 4.7 & 30.0 & 48.724 \\
\hline EU-25 average & 9.1 & 27.4 & 9.855 \\
\hline
\end{tabular}

(Source: Eurostat website under http://epp.eurostat.cec.eu.int/) 
Table 2: Simulation Results

\begin{tabular}{|c|c|c|c|c|c|}
\hline \multicolumn{2}{|l|}{ regime } & $\begin{array}{r}\text { unemployment rate } \\
\text { (in percent) }\end{array}$ & $\begin{array}{r}\text { tax rate } \\
\text { (in percent) }\end{array}$ & $\begin{array}{r}\text { tax revenue } \\
\text { (in billion euro) }\end{array}$ & welfare \\
\hline \multicolumn{2}{|l|}{ separate accounting } & 9.10 & 27.40 & 9.855 & 59.570 \\
\hline \multicolumn{2}{|l|}{ efficient solution } & 4.41 & 14.66 & 5.411 & 59.838 \\
\hline \multicolumn{6}{|c|}{ formula apportionment by ... } \\
\hline ...pproperty: & $(\gamma, \sigma, \varphi)=(1,0,0)$ & 2.04 & 7.10 & 2.652 & 59.762 \\
\hline ... payroll: & $(\gamma, \sigma, \varphi)=(0,0,1)$ & 0.06 & 0.00 & 0.000 & 59.571 \\
\hline ... sales: & $(\gamma, \sigma, \varphi)=(0,1,0)$ & 3.86 & 13.00 & 4.812 & 59.834 \\
\hline ... Massachusetts: & $(\gamma, \sigma, \varphi)=(1 / 3,1 / 3,1 / 3)$ & 0.45 & 1.47 & 0.554 & 59.619 \\
\hline ... double sales: & $(\gamma, \sigma, \varphi)=(1 / 4,1 / 2,1 / 4)$ & 1.12 & 3.87 & 1.453 & 59.688 \\
\hline
\end{tabular}

(parameter values: $\alpha=0.3, \beta=0.35, \nu=0.35, \kappa=1.325, r=1.05, \rho=0.69, \zeta=0.0265, q=21206.5, w=29.8026$, )

Table 3: Externalities

\begin{tabular}{|c|c|c|c|c|c|c|c|}
\hline \multicolumn{2}{|l|}{ regime } & IE & PE & UE & TE & FE & $\Sigma$ \\
\hline \multicolumn{2}{|l|}{ separate accounting } & -17.98 & 13.46 & - & - & - & -4.53 \\
\hline \multicolumn{8}{|c|}{ formula apportionment by ... } \\
\hline ...pproperty: & $(\gamma, \sigma, \varphi)=(1,0,0)$ & -18.68 & - & 15.71 & -0.25 & 5.14 & 1.94 \\
\hline ... payroll: & $(\gamma, \sigma, \varphi)=(0,0,1)$ & -18.85 & - & 33.74 & 0.00 & 0.00 & 14.89 \\
\hline ... sales: & $(\gamma, \sigma, \varphi)=(0,1,0)$ & -18.51 & - & 16.47 & -0.51 & 3.02 & 0.46 \\
\hline ... Massachusetts: & $(\gamma, \sigma, \varphi)=(1 / 3,1 / 3,1 / 3)$ & -18.81 & - & 21.42 & -0.05 & 0.56 & 3.12 \\
\hline ... double sales: & $(\gamma, \sigma, \varphi)=(1 / 4,1 / 2,1 / 4)$ & -18.76 & - & 20.21 & -0.13 & 1.31 & 2.64 \\
\hline
\end{tabular}




\title{
CESifo Working Paper Series
}

\author{
(for full list see www.cesifo-group.de)
}

1808 Axel Dreher, Jan-Egbert Sturm and James Raymond Vreeland, Does Membership on the UN Security Council Influence IMF Decisions? Evidence from Panel Data, September 2006

1809 Prabir De, Regional Trade in Northeast Asia: Why do Trade Costs Matter?, September 2006

1810 Antonis Adam and Thomas Moutos, A Politico-Economic Analysis of Minimum Wages and Wage Subsidies, September 2006

1811 Guglielmo Maria Caporale and Christoph Hanck, Cointegration Tests of PPP: Do they also Exhibit Erratic Behaviour?, September 2006

1812 Robert S. Chirinko and Hisham Foad, Noise vs. News in Equity Returns, September 2006

1813 Oliver Huelsewig, Eric Mayer and Timo Wollmershaeuser, Bank Behavior and the Cost Channel of Monetary Transmission, September 2006

1814 Michael S. Michael, Are Migration Policies that Induce Skilled (Unskilled) Migration Beneficial (Harmful) for the Host Country?, September 2006

1815 Eytan Sheshinski, Optimum Commodity Taxation in Pooling Equilibria, October 2006

1816 Gottfried Haber and Reinhard Neck, Sustainability of Austrian Public Debt: A Political Economy Perspective, October 2006

1817 Thiess Buettner, Michael Overesch, Ulrich Schreiber and Georg Wamser, The Impact of Thin-Capitalization Rules on Multinationals' Financing and Investment Decisions, October 2006

1818 Eric O’N. Fisher and Sharon L. May, Relativity in Trade Theory: Towards a Solution to the Mystery of Missing Trade, October 2006

1819 Junichi Minagawa and Thorsten Upmann, Labor Supply and the Demand for Child Care: An Intertemporal Approach, October 2006

1820 Jan K. Brueckner and Raquel Girvin, Airport Noise Regulation, Airline Service Quality, and Social Welfare, October 2006

1821 Sijbren Cnossen, Alcohol Taxation and Regulation in the European Union, October 2006

1822 Frederick van der Ploeg, Sustainable Social Spending in a Greying Economy with Stagnant Public Services: Baumol’s Cost Disease Revisited, October 2006 
1823 Steven Brakman, Harry Garretsen and Charles van Marrewijk, Cross-Border Mergers \& Acquisitions: The Facts as a Guide for International Economics, October 2006

1824 J. Atsu Amegashie, A Psychological Game with Interdependent Preference Types, October 2006

1825 Kurt R. Brekke, Ingrid Koenigbauer and Odd Rune Straume, Reference Pricing of Pharmaceuticals, October 2006

1826 Sean Holly, M. Hashem Pesaran and Takashi Yamagata, A Spatio-Temporal Model of House Prices in the US, October 2006

1827 Margarita Katsimi and Thomas Moutos, Inequality and the US Import Demand Function, October 2006

1828 Eytan Sheshinski, Longevity and Aggregate Savings, October 2006

1829 Momi Dahan and Udi Nisan, Low Take-up Rates: The Role of Information, October 2006

1830 Dieter Urban, Multilateral Investment Agreement in a Political Equilibrium, October 2006

1831 Jan Bouckaert and Hans Degryse, Opt In Versus Opt Out: A Free-Entry Analysis of Privacy Policies, October 2006

1832 Wolfram F. Richter, Taxing Human Capital Efficiently: The Double Dividend of Taxing Non-qualified Labour more Heavily than Qualified Labour, October 2006

1833 Alberto Chong and Mark Gradstein, Who’s Afraid of Foreign Aid? The Donors' Perspective, October 2006

1834 Dirk Schindler, Optimal Income Taxation with a Risky Asset - The Triple Income Tax, October 2006

1835 Andy Snell and Jonathan P. Thomas, Labour Contracts, Equal Treatment and WageUnemployment Dynamics, October 2006

1836 Peter Backé and Cezary Wójcik, Catching-up and Credit Booms in Central and Eastern European EU Member States and Acceding Countries: An Interpretation within the New Neoclassical Synthesis Framework, October 2006

1837 Lars P. Feld, Justina A.V. Fischer and Gebhard Kirchgaessner, The Effect of Direct Democracy on Income Redistribution: Evidence for Switzerland, October 2006

1838 Michael Rauscher, Voluntary Emission Reductions, Social Rewards, and Environmental Policy, November 2006

1839 Vincent Vicard, Trade, Conflicts, and Political Integration: the Regional Interplays, November 2006 
1840 Erkki Koskela and Mikko Puhakka, Stability and Dynamics in an Overlapping Generations Economy under Flexible Wage Negotiation and Capital Accumulation, November 2006

1841 Thiess Buettner, Michael Overesch, Ulrich Schreiber and Georg Wamser, Taxation and Capital Structure Choice - Evidence from a Panel of German Multinationals, November 2006

1842 Guglielmo Maria Caporale and Alexandros Kontonikas, The Euro and Inflation Uncertainty in the European Monetary Union, November 2006

1843 Jan K. Brueckner and Ann G. Largey, Social Interaction and Urban Sprawl, November 2006

1844 Eytan Sheshinski, Differentiated Annuities in a Pooling Equilibrium, November 2006

1845 Marc Suhrcke and Dieter Urban, Are Cardiovascular Diseases Bad for Economic Growth?, November 2006

1846 Sam Bucovetsky and Andreas Haufler, Preferential Tax Regimes with Asymmetric Countries, November 2006

1847 Luca Anderlini, Leonardo Felli and Andrew Postlewaite, Should Courts always Enforce what Contracting Parties Write?, November 2006

1848 Katharina Sailer, Searching the eBay Marketplace, November 2006

1849 Paul De Grauwe and Pablo Rovira Kaltwasser, A Behavioral Finance Model of the Exchange Rate with Many Forecasting Rules, November 2006

1850 Doina Maria Radulescu and Michael Stimmelmayr, ACE vs. CBIT: Which is Better for Investment and Welfare?, November 2006

1851 Guglielmo Maria Caporale and Mario Cerrato, Black Market and Official Exchange Rates: Long-Run Equilibrium and Short-Run Dynamics, November 2006

1852 Luca Anderlini, Leonardo Felli and Andrew Postlewaite, Active Courts and Menu Contracts, November 2006

1853 Andreas Haufler, Alexander Klemm and Guttorm Schjelderup, Economic Integration and Redistributive Taxation: A Simple Model with Ambiguous Results, November 2006

1854 S. Brock Blomberg, Thomas DeLeire and Gregory D. Hess, The (After) Life-Cycle Theory of Religious Contributions, November 2006

1855 Albert Solé-Ollé and Pilar Sorribas-Navarro, The Effects of Partisan Alignment on the Allocation of Intergovernmental Transfers. Differences-in-Differences Estimates for Spain, November 2006 
1856 Biswa N. Bhattacharyay, Understanding the Latest Wave and Future Shape of Regional Trade and Cooperation Agreements in Asia, November 2006

1857 Matz Dahlberg, Eva Mörk, Jørn Rattsø and Hanna Ågren, Using a Discontinuous Grant to Identify the Effect of Grants on Local Taxes and Spending, November 2006

1858 Ernesto Crivelli and Klaas Staal, Size and Soft Budget Constraints, November 2006

1859 Jens Brøchner, Jesper Jensen, Patrik Svensson and Peter Birch Sørensen, The Dilemmas of Tax Coordination in the Enlarged European Union, November 2006

1860 Marcel Gérard, Reforming the Taxation of Multijurisdictional Enterprises in Europe, “Coopetition” in a Bottom-up Federation, November 2006

1861 Frank Blasch and Alfons J. Weichenrieder, When Taxation Changes the Course of the Year - Fiscal Year Adjustments and the German Tax Reform 2000/2001, November 2006

1862 Hans Jarle Kind, Tore Nilssen and Lars Sørgard, Competition for Viewers and Advertisers in a TV Oligopoly, November 2006

1863 Bart Cockx, Stéphane Robin and Christian Goebel, Income Support Policies for PartTime Workers: A Stepping-Stone to Regular Jobs? An Application to Young LongTerm Unemployed Women in Belgium, December 2006

1864 Sascha O. Becker and Marc-Andreas Muendler, The Effect of FDI on Job Separation, December 2006

1865 Christos Kotsogiannis and Robert Schwager, Fiscal Equalization and Yardstick Competition, December 2006

1866 Mikael Carlsson, Stefan Eriksson and Nils Gottfries, Testing Theories of Job Creation: Does Supply Create Its Own Demand?, December 2006

1867 Jacques H. Drèze, Charles Figuières and Jean Hindriks, Voluntary Matching Grants Can Forestall Social Dumping, December 2006

1868 Thomas Eichner and Marco Runkel, Corporate Income Taxation of Multinationals and Unemployment, December 2006 